\title{
Marketing Curriculum Design and Application Research Based on Revised Edition of Bloom's Educational Objective Taxonomy
}

\author{
Chunying Wang \\ College of Economics and Management, Jilin Agricultural Science and Technology University \\ Jilin 132101
}

\begin{abstract}
The revised edition of Bloom's Educational Objectives Taxonomy, combined with modern cognitive psychology, solves the problem of transforming declarative knowledge into procedural knowledge and metacognitive knowledge, and achieves the consistency audit of teaching objectives, teaching activities and assessment. As the core curriculum of management major, in order to better realize the concept of applied education, marketing curriculum should construct a classification system of teaching objectives to adapt to the development of the times, improve curriculum system, and enrich the teaching design framework and evaluation methods of marketing knowledge classification.
\end{abstract}

Keywords-Bloom's taxonomy of educational objectives; Marketing teaching objectives; Classification of teaching objectives

\section{BLOOM'S TAXONOMY OF EDUCATIONAL OBJECTIVES AND ITS REVISED EDITION}

In 1956, the classification system of educational objectives [1] is proposed in the book Taxonomy of Educational Objectives, Classification of Instructional Objectives, Handbook I: Cognitive Domain edited by B.S Bloom and prepared by M. D Engelhardt et al. Bloom et al. believe that objectives in life will help people focus and work hard, and objectives can indicate the mission required to complete. In education, objectives can indicate expected student learning outcomes [1]. In teaching, the objectives are particularly important, because teaching is a purposeful rational behavior. Teachers' teaching behavior is the behavior of teaching for a certain purpose, as well as the behavior of helping students to learn. The rationality of teaching involves what the teacher chooses for the students, and the purposefulness relates to how the teacher helps the students to achieve the goal. Teachers' objectives may be explicit or implicit, explicit or vague, easy to measure or difficult to measure. This objective is also called a purpose, an intention, or a teaching outcome. Bloom et al. proposed that because teachers face a large number of objectives in the teaching process, they need to organize these objectives in some way to improve the accuracy of the meaning of goals [1]. Its nature is to classify the teaching objectives according to certain organizational principles. The characteristics of a certain category and other categories after classification can help teachers to better understand the content under the category. On this basis, they divide the educational objectives into six levels: knowledge, understanding, application, analysis, synthesis and evaluation.

In 2001, Anderson et al, together with some cognitive psychologists, curriculum and teaching experts and measurement and evaluation experts, revised the 1956 version of the classification system (or framework) of educational objectives. The revised classification system (or framework) of educational objectives has two dimensions, namely, cognitive process dimension and knowledge dimension. The dimension of cognitive process includes memory, understanding, application, analysis, evaluation and creation. The order is assumed to be based on cognitive complexity, that is, understanding is considered more complex than memory in cognition, and application is more complex than understanding in cognition, and so on. Knowledge dimension includes factual knowledge, conceptual knowledge, procedural knowledge and metacognitive knowledge. Anderson et al. assume that these categories are arranged in order from concrete (factual knowledge) to abstract (metacognitive knowledge); However, conceptual knowledge and procedural knowledge overlap in abstraction degree, and some procedural knowledge may be more concrete than most abstract conceptual knowledge[2]. Knowledge dimension and cognitive process dimension constitute the two-dimensional framework of educational objectives. By understanding the specific meanings of "knowledge dimension" and "cognitive process dimension", teachers can determine the specific position of their teaching objectives in the classification table, improve their understanding of the objectives, further plan teaching activities, design evaluation consistent with the teaching content, and improve teaching quality.

\section{CONSTRUCTION AND CLASSIFICATION OF MARKETING TEACHING OBJECTIVES BASED ON REVISED EDITION OF BLOOM'S TAXONOMY OF EDUCATIONAL OBJECTIVES}

\section{A. Construction of Marketing Teaching Objectives Based on Revised Edition of Bloom's Taxonomy of Educational Objectives}

Marketing course, as a full-time undergraduate management-related core curriculum, its status and role cannot be underestimated. In order to improve students' marketing ability and skills, embody the ability-based thinking, combined 
with theory related to revised version of Bloom's taxonomy of educational objectives, from the perspective of cognitive process, the curriculum system is divided into four modules, respectively, understand marketing, find market opportunities, determine the target market, formulate marketing strategies. According to target requirements in the revised edition Bloom's Taxonomy of Educational Objectives, the expression of educational objectives needs to include a verb and a noun, verb describes the expected cognitive process, and noun describes the knowledge that teachers or trainers expect students to acquire or construct. Its nature is to replace "behavior" with "cognitive process" and replace "content" with "knowledge". This expression by the teacher or trainer is made intentionally to allow for a more detailed examination of the objectives and to further define their specific place in the Bloom classification system (or framework) of educational objectives. Combined with the Chinese version of marketing textbook translated by Yonggui WANG and compiled by Gary Armstrong and Philip Kotler, this paper puts forward the general objectives, educational objectives and teaching objectives of marketing course. The general objective is to take a lot of time and teaching efforts to achieve complex and multi-faceted results, and marketing course as a management-related backbone curriculum, students is set to make students master basic marketing vocational ability and vocational marketing quality through learning. The general objective of the curriculum is to provide a vision of the future and a battle cry for policymakers, curriculum developers, teachers and the general public [3]. These objectives are rough indications of the important elements that good education is supposed to encompass [1]. The general objective is currently unattainable and as a structure which needs to be fought for, to move towards or to be achieved, it is more like to a purpose or an intention. They need to be broken down into more targeted and explicit objective so that teachers can use them for planning and teaching. Therefore, on this basis, combined with the marketing textbook system, the overall objective will be further decomposed into slightly more specific objectives. These objectives are called educational objectives. The educational objectives of marketing are mainly four specific objectives determined according to its modules, namely, the ability to explain what marketing is, the ability to analyze the marketing environment, the ability to judge the target market and the ability to design marketing mix strategy. Such kind of education objectives are located in the middle of the objective continuum, and they are more specific than the general objective, but more comprehensive than the objective that teachers use to guide the daily teaching needs, which leads to more specific teaching objectives than the education goal.

\section{B. Classification of Marketing Teaching Objectives Based on Revised Edition of Bloom's Taxonomy of Educational Objectives}

Bloom's taxonomy of educational objectives is to classify the teaching objectives set by teachers or trainers in its table of knowledge dimension and cognitive process dimension, and to clarify the learning problems according to their specific location. Combined with the definite learning problems, teachers need to design corresponding teaching activities in order to achieve a clear teaching objective. Teaching activities are activities that help students to develop knowledge about certain learning problems. This activity can provide opportunities for students to develop at least conceptual knowledge, procedural knowledge and metacognitive knowledge, which also involves five cognitive process categories - memory, understanding, application, analysis and evaluation [4]. Teachers design and implement teaching activities according to teaching objectives, and teachers must make some decisions in order to understand students' learning situation. The most important thing is how to evaluate its teaching effect and students' learning effect. At this time, the content of teachers' assessment determines the specific form of assessment. In the process of teaching, if the teacher pays attention to the understanding of conceptual knowledge, the assessment form is mainly centralized assessment or distributed assessment; If teachers' pay more attention to students' analysis of conceptual knowledge, it is more likely that the formative assessment form will be adopted. If a teacher carried out independent assessment in order to evaluate the learning effect of students, chooses and implements procedural knowledge, then the evaluation method adopted by the teacher is summative evaluation.

According to Bloom's classification theory of educational objectives, this paper classifies the "verbs" and "nouns" in the teaching objectives of marketing course, so as to further determine their specific positions in the classification table. Combined with the position of each teaching objective in the classification table, determine the learning problems, teaching activities and evaluation form. For example, in module 4 of Marketing Course, one of the teaching objectives in the formulation of marketing strategies is to identify pricing strategies. "Identification" belongs to the "analysis" dimension in the cognitive process dimension, and "pricing strategies" belongs to the "metacognitive knowledge" in the knowledge dimension. This teaching objective is shown in Table 1 , box D4. The learning problem of this teaching objective is hoping that students can distinguish metacognitive knowledge; Combined with the analysis of teaching objectives, teachers' teaching activities can be designed as follows: Activities 1 understand metacognitive knowledge (understand different pricing strategies), Activities 2 - apply metacognitive knowledge (use different pricing strategies), Activities 3 apply procedural knowledge (how to set product price) or Activities 4 - evaluate metacognitive knowledge (evaluate the application of different pricing strategies). Combined with the above teaching activities, teachers can choose the appropriate assessment methods according to the specific learning problems, such as understanding different pricing strategies can allow them to assess the students' understanding of the conceptual knowledge through the expression of concepts or by means of seat by number; Student's understanding of the pricing process can be determined by how they describe the pricing process. The application of assessment pricing strategy can be evaluated by case analysis. 
TABLE I

Classification of Teaching ObJectives of Marketing Courses

\begin{tabular}{|c|c|c|c|c|c|c|}
\hline \multirow{2}{*}{$\begin{array}{l}\text { Knowledge } \\
\text { dimension }\end{array}$} & \multicolumn{6}{|c|}{ Cognitive process dimension } \\
\hline & 1.Remember & 2.Understand & 3.Apply & 4.Analyze & 5.Evaluate & 6. Cerate \\
\hline $\begin{array}{l}\text { A.Factual } \\
\text { Knowledge }\end{array}$ & & & & & & \\
\hline $\begin{array}{l}\text { B.Conceptual } \\
\text { Knowledge }\end{array}$ & & & & & & \\
\hline $\begin{array}{l}\text { C.Procedural } \\
\text { Knowledge }\end{array}$ & & & & Activity 3 & & \\
\hline $\begin{array}{l}\text { D.Metacognitive } \\
\text { Knowledge }\end{array}$ & & Activity 1 & Activity 2 & $\begin{array}{ll}\text { Objective } & \\
\text { Identify } & \text { pricing } \\
\text { strategies } & \end{array}$ & Activity 4 & \\
\hline
\end{tabular}

Combined with the revised edition of Bloom's taxonomy of educational objectives, the classification of teaching objectives of marketing course can help teachers to improve the teaching objectives of the course. Determining the position in teaching objectives classification table can help teachers sort out the specific content and ideas of teaching activity design, and further determine the reasonable evaluation method. According to the above content, teachers can better examine their teaching objectives, teaching activities and evaluation consistency through the classification table.

\section{The APPliCATION OF REVISED EDITION OF BLOOM'S TAXONOMY OF EDUCATIONAL OBJECTIVES IN MARKETING COURSE}

The Revised Edition of Bloom's Taxonomy of Educational Objectives further defines the specific position of the objective in the classification table by judging its cognitive dimension and the knowledge dimension involved in the teaching objective through the expression form of the teaching objective, and further defines the learning problem, that is, the problem of what students learn. In order to achieve this teaching objective, teachers need to adopt some teaching activities, to achieve the expected teaching objectives through the specific strategies of teaching activities. And how to know whether the students have mastered the relevant knowledge, it is necessary to evaluate the teaching results.

\section{A. Setting of Marketing Teaching Objectives}

The teaching design of marketing course begins with the establishment of its teaching objectives. For teachers or trainers, what they think about is what students will do after learning, not what they will learn. Therefore, when describing the teaching objectives of marketing course, students' behaviors are usually described in the form of objectives. Teachers can clearly observe and evaluate students' learning results through specific behavioral descriptions. In the course of dividing the curriculum system of marketing, the expression form of "verb" and "noun" in Bloom's taxonomy of educational objectives is also used, which includes understanding marketing, finding market opportunities, determining target market and formulating marketing strategies. Through this expression, it provides a more effective starting point and end-result for the teaching design of teachers, but also allows teachers to clearly know how to evaluate students' learning results.

\section{B. Choice of Teaching Strategies for Marketing Course}

In Revised Edition of Blooms of Taxonomy of Educational Objectives, teaching activities are also the choice of teaching strategies, which are further implemented on the basis of defining the types of learning outcomes, the paths to learning outcomes and the corresponding teaching activities designed according to the paths [6]. In the teaching process of marketing course, "understanding marketing", "finding market opportunities", "determining target market", "formulating marketing strategy" are all the expected learning outcomes. On the basis of clearly and accurately stating the objectives, it is necessary to analyze the design of teaching activities of these educational objectives. At this time, teachers need to be clear about what conditions are required to achieve these expected learning outcomes, further solve the choice of teaching methods, and achieve educational objectives. In this process, the required conditions determine the choice of teaching methods and strategies. For example, in the teaching link of "understanding marketing", teachers' instructional design needs to consider the conditions of "students' understanding of marketing concepts", which includes the understanding of marketing-related terms and specific cases in life. At this time, teachers' instructional design can consider enhancing the understanding of marketing concepts by retelling factual knowledge in real life and using positive and negative cases.

\section{Selection of Evaluation Forms for Marketing Teaching Results}

Bloom's classification theory of educational objectives emphasizes that the classification of teaching objectives can help teachers determine a reasonable form of assessment. For example, in the link of understanding marketing, students can show their understanding of the concept by means of selfmarketing. In the link of finding market opportunities, students can use learned methods and knowledge through the analysis of the actual environment. In the link of determining target market, the target market can be selected through the analysis of the basic market situation and product characteristics; In the process of making marketing strategy, we can combine the above analysis and use relevant methods to formulate marketing strategy.

In addition, revised edition of Bloom's taxonomy of educational objectives can not only guide teachers to choose a reasonable form of assessment, but also help teachers to set a reasonable learning outcome scoring rules. For example, if the student understands the concept of marketing (understanding conceptual knowledge), score 1 point; If students can analyze 
what marketing is (analyze conceptual knowledge), score 1 point; If students can, based on the situation, analyze which marketing concept it is (analyze procedural knowledge), score 1 point; If students can market themselves, score 1 point [5] The specific position of teaching objectives in the classification table can help teachers to choose the appropriate evaluation form and determine the evaluation details, which is conducive to better evaluate students' learning results and teachers' teaching effect.

\section{CONCLUSIONS}

The revised version of Bloom's taxonomy of educational objectives helps teachers understand the curriculum, plan teaching and design evaluation consistent with the curriculum's internal objectives, and ultimately improve the quality of teaching [1]. Under the guidance of this theory, combined with Chinese version of marketing textbook translated by Yonggui WANG and complied by Gary Armstrong and Philip Kotler, the construction and classification of teaching objectives of marketing course are completed, the curriculum system is improved, and the teaching design ideas and evaluation forms of marketing knowledge classification are enriched.

\section{ACKNOWLEDGMENT}

This paper is the phased research results for "Research on Blended Learning Model of Marketing Course Based on WeChat Public Platform" (Project No. ZD17110), which is the subject of the "13th Five-Year Plan" of Jilin Education Science in 2017, the "Blended Instructional Design and Application of Marketing Course Based on Educational Objective Classification" (Project No.: JGJX2018D233), which is the 2018 Project of Jilin Provincial Institute of Higher Education, and the key discipline construction project of business administration in Jilin Agricultural Science and Technology College.

Chunying Wang, lecturer, teacher of Marketing Department, School of Economics and Management, Jilin Agricultural Science and Technology University.

\section{REFERENCES}

[1] Lorin W. Anderson, et al. Revised Edition of Bloom's Taxonomy of Educational Objectives Learning, Teaching and Evaluation from the Taxonomic Perspective [M]. Translated by Xiaoping JIANG. Beijing: FLTRP, 2009.

[2] Lorin W. Anderson et al. Taxonomy of Learning, Teaching and Evaluation: Revised Edition of Bloom's Taxonomy of Educational Objectives [M]. Translated by Liansheng PI, Shanghai: East China Normal University Press, 2008

[3] Bochang ZHONG, Yi LI. How core quality is implemented: Turn from Horizontal Classification to Horizontal Stratification [J]. Journal of east China normal university ((Educational Science Edition),2018, 36(01): 55-63+161-162.

[4] Chunlin LIU, Qixin PAN, Hui YANG. Bloom's Taxonomy of Educational Objectives (Revised Edition) and Its Application in the Basic Course of Computer Application in University [J]. Computer Knowledge and Technology, 2018,14(20): 152-153.

[5] Wenjuan LI, Yanfang LI. On English classroom teaching design in higher vocational colleges--Based on the perspective of integration of multiple intelligences theory and Bloom's taxonomy of educational objectives [J]. Higher Vocational Education (Journal of Tianjin Vocational University), 2018, 27 (04): 40-43.

[6] Chunli ZHANG, Xiaodan MA. The Application of Revised Edition of Bloom's Taxonomy of Educational Objectives in Mathematics [J]. Courses. Textbooks. Education Methods, 2017,37(01): 119-124. 